\title{
Antecedents of Organic Food Products Intention and Behaviors: Evidence from Vietnam
}

\author{
Hung Cuong PHAM ${ }^{1}$
}

Received: November 15, 2019 Revised: August 13, 2020 Accepted: October 05, 2020

\begin{abstract}
The paper investigates the antecedents of Organic Food (OF) produce in Vietnam and the intentions and behavior of OF purchasers. A theoretical framework is developed and evaluated by simulation of the structural model. Data was collected from a convenient sample of 222 consumers from Ho Chi Minh City in Vietnam. The selection included $159(72 \%)$ women, who were identified as being the primary buyers of organic food for their family (73\%). Findings suggest food hygiene issues and conscientious self-identity as the much beneficial determinants of organic production perceptions. Because of the results in this report, the consideration for food security has gained little research consideration throughout the field of organic produce. Food safety concerns are also related to academics exploring consumer confidence as they might be regarded as one of their aspects in selecting standard, natural or health food products. Findings suggest food security as one of the essential determinants of motivation, while health awareness purports to become the least significant motivation, contrary to observations from certain previous studies. However, it is observed that moral personality-identity influences both perceptions and willingness to buy organic food, stressing that the association of participants with ethical concerns influences their perceptions and eventual choices of consumption.
\end{abstract}

Keywords: Organic Food, Organic Produce, Product Safety, Rational Self-Identity, Simulation of Computational Equations, Perceptions Expectations, Consumers

JEL Classification Code: L81, M10, M31

\section{Introduction}

In several developing nations, organic food (OF) has received attention due to potential benefits for the government sector as well as the private sector's global trade interaction. OF's worldwide sales grow above USD5 billion annually and tend to be increasing in the future years (Willer $\&$ Klicher, 2009). In general, because of the relatively rapid increase in population as well as markets, the Asian market has been an essential source and exporter of OF. The growth of the OF sector is backed not just by customers, industry providers and government agencies, but also by the

${ }^{1}$ First Author and Corresponding Author. Manager, Scientific Management and International Cooperation Department, Foreign Trade University, Ho Chi Minh City Campus, Vietnam [Postal Address: 15D5, Ward 25, Binh Thanh District, Ho Chi Minh City, 700000, Vietnam] Email: phamhungcuong.cs2@ftu.edu.vn

(c) Copyright: The Author(s)

This is an Open Access article distributed under the terms of the Creative Commons Attribution Non-Commercial License (https://creativecommons.org/licenses/by-nc/4.0/) which permits unrestricted non-commercial use, distribution, and reproduction in any medium, provided the original work is properly cited. understanding and expectations of end users about organic produce. Numerous scientific and social analyzes on $\mathrm{OF}$ and OF buyers in different parts of the world have already been performed. Nevertheless, there are studies simply on the perception of OF by current and prospective customers in Asian nations (Roitner et al., 2008). Cox (2007), therefore, suggested the need for more scientific studies to consider Asian customers of OF.

The goal of this paper is to evaluate why prospective Vietnamese customers (PVC) intend to buy OF; to analyze PVCs demographic profiles and to establish OF's impressions of PVC in comparison to their purchasing expectations. Not only do the findings contribute to an understanding of $\mathrm{OF}$ in Vietnam, but they will also point to suggestions. Vietnamese OF producers and distributors might pursue potential consumers to broaden their established OF market. OF's primary purpose is to optimize food production by monitoring human, fauna, flora and ground health, and wellbeing concerns through a collection of strict rules and complex processes. OF is grown and harvested without the need for artificial fertilizers, insecticides, expansion regulators, feed additives for animals, and scientifically-modified organisms 
to ensure the consistency of end-used food items. However, Winter and Davis (2006) have established that OF is generated through a natural process that increases ecological cycles, decreases emissions, and at the same time provides a safe and stable environment for animals and producers. OF may, indeed, contain multiple contaminants from unintentional soil and pollution of the ecosystem. OF and conventional foods (CF) are fundamentally distinct. Cultivation of $\mathrm{OF}$ is the sustainable growth of agriculture since it assists in decreasing toxic, noxious fumes through chemical use in cultivation.

Besides, organic farming can preserve wildlife and reservoirs from pollution with pesticides, and consumers from toxic chemicals in nutrition. Organic farming increases the habitat of natural fauna and flora, enhances soil quality, decreases agricultural pollution and effectively uses energy. Therefore, OF will assist in improving environmental protection as organic livestock are raised in biologicallyideal conditions to ensure their safety and expected behavior (Sorensen \& Andreasen, 2006). The OF development produces naturally lower yields and is locally farmed to promote management of inputs and outputs to assist smaller farms and national economy. Eventually, organic farming can be a safe way of producing sufficiently healthy food to mitigate food shortages as well as the current increasing global demographics. The food production utopia, indeed, depends on preparation, skilled workforce, research and technology, ecology, and financial capital. Organic produce appears better than conventional produce, but that traditional and organic fruit juice does not vary in taste. Organicallygrown fruits and vegetables in distinct style taste great, and tastier are natural tomatoes. OF has more nutritional benefits than conventional food.

\section{Literature Review and Hypotheses}

\subsection{Literature Review}

Modeling of structural equations is a method of quantitative analysis employed to analyze relational interactions. The approach has been the synthesis of factor assessment and evaluation of multiple regressions and has been used to evaluate the structural interaction between observable variables and implicit concepts. The approach in a single study measures numerous and interconnected dependency. In such examination, endogenous parameters and regression coefficients are employed in two categories of parameters. Endogenous parameters are equal to reliant factors and the autonomous parameter.

OF has significantly higher concentrations of 21 nutritive elements relative to $\mathrm{CF}$ products. Productivity and usage are, in both categories, seen as a decent method of keeping prospective dangerous chemicals out and into fresh produce and protecting public health and safety. OF not only helps the well-being of customers, but the health of producers. While producing OF, farmers will decrease their exposure to chemical fertilizers and, thus, increase their wellbeing. OF consumers are presently concentrated in Europe and North America, accounting for $97 \%$ of the world customers. OF is grown using sustainable farming practices and without using standard methods such as cosmic radiation or biotechnology, phosphate fertilizers or artificial ingredients. Non-use of synthetic pesticides helps food products to generate $40 \%$ less energy and promote livestock, soil and environmental welfare. Consumers of organic foods see it as a healthier alternative, a better quality, and tastier than CFs. Because of its possible benefits, the global trading of organic produce has experienced unprecedented development. The U.S. industry accounts for the largest proportion of international OF transaction, rising from USD3.4 billion in 1999 to USD45 billion in 2017, whereas the European Union stood second, selling USD33.5 billion in 2016. While most natural foods intake exists in industrialized countries ( $90 \%$ of total intake), most $\mathrm{OF}$ is grown in developing economies, particularly in South Asian nations.

Throughout the Asian region, manufacturers of organic products have grown dramatically between 2015 and 2016 and have been anticipated to increase by $370 \%$ over the next ten years, the largest of any region. Pakistan has indeed an economy with a $20 \%$ agricultural input to the aggregate gross domestic product of South Asia. Pakistan has become an organic food production country with such an implanted region of 45,299 acres, with a maximum nurtured part of 22,68 million acres and 111 resource producers, but with the participation of only $0,1 \%$ to the international organic sector. However, given the benefits and ability of organic produce, natural foods acceptance in organic food-producing nations is still low. In contrast, most families devote more than half of their income on food items (Liang, 2014). It is therefore essential for marketing companies to define factors that promote $\mathrm{OF}$ intake to comprehend the motivations of customers about their dietary patterns better as well as to develop marketing campaigns to raise sales. Previous studies identified many significant factors correlated with the acquisition of organic produce, such as health awareness, quality, reliability, ratings, taste, product safety as well as availability.

There should be a comparative analysis between businesses of environmentally-friendly specialty stores through suburban agriculture and producer's agriculture connected with organic farming market (Kim et al., 2014). There is a positive attitude of customers toward the intention of acquiring organic cosmetics, perceived as green products, and customer satisfaction. In addition, customer satisfaction, knowledge of products, safety values, and environmentalprotection consciousness also play important roles to form a positive attitude of customers for products (Nguyen et al., 
2019). Environmental concerns had a positive impact on such practices, and the image of internal green supply chain management practices was found to have a significantly positive effect on consumer purchasing behavior (Lee et al., 2020). Consumers have paid no attention to the marketing mix factors, but they care much about service quality and health consciousness (Tran et al., 2020). There have been some gaps found by scholars, following some critical early studies. Firstly, less attention has been paid to organic produce intake, particularly in Vietnam, that has become one of the essential organic produce sections. It is of paramount importance to consider consumer expectations, behaviors and buying actions concerning healthy foods. Some recent articles emphasize diet and nutrition data and information; behavioral and interpersonal backgrounds such as mindsets, expectations and opinions; brand characteristics; and cultural-demographic parameters, as essential to choice and competition regarding functional food products. As for dietary decisions, in particular, there are many and sophisticated explanations for purchasing and eating healthy food products. While the results are contradictory and inconsistent, the approval of organic food is closely connected to consumer trust in its overall health value or potential consumer incentive (Siegrist et al., 2015).

The apparent need for responsive food products for the community as a whole, trust in them, and well-being of valuable food products and perceptual characteristics including (good) taste. Products can offer the advantages of a physiological or functional existence. Hedonic commodities provide more conceptual use, conveying fun, enjoyment, anticipation, satisfaction, imagination or pleasure, while utilitarian goods are mainly operational, practical, purposeoriented, and self-control-related (Alba \& Williams, 2013). For food choices, in particular, physiological characteristics or principles are essential. Although organic products provide physiological and utilitarian attributes, comparatively, healthy foods are proposed to be advantageous in the delivery of practical incentives. Consumer buying patterns include determinations that the customer wants to purchase over time about services and goods. Among different product classes, such intentions differ, particularly among ecological (green) products, since consumers buying natural products have other motives than any of those buying conventional products.

The green perceived value (GPV) model will illustrate these reasons, explaining why customers prefer to purchase or not purchase organic goods as well as why customers choose a particular brand over others. Throughout the articles on green advertising, and why would people prefer a specific brand to others? GPV is regarded as an essential factor in deciding the use of organic foods throughout the green promotion discourse and ecological research. GPV is described as "the overall customer evaluation of the net benefits of goods or services between what is provided and what is anticipated centered on the ecological preferences of the customer, conservation aspirations and ecological needs". Throughout the choice-making process, GPV makes it easier to comprehend the needs, preferences and desires of customers from green goods that cannot be clarified by a onedimensional definition.

Because of the complicated system of GPV, Sangroya and Kumar (2017) established a multifaceted GPV system that includes four environmentally-friendly apparent principles, which determine consumer inclination: practical, cultural, psychological, and epistemological ideals. These principles predict the actions of customers to consume the specific green commodity, organic goods in such a scenario. While GPV's projected expectations result in the observed purchasing actions of a particular product, Woo and Kim (2019) suggest that the specific purchasing activity of OF should be tested using the GPV method. Besides, prior studies also indicate that motives are good conduct determinants, but often there is a significant difference between incentives and behavior. Food phenotypic plasticity might be one of the fundamental reasons for the low implementation of organic produce or this actual intent-behavior disparity. Neophobia in food relates to the unwillingness or unwillingness of customers to try different, unknown and healthy foods. For additional products such as organic foods, nutrition neophobia influences the thoughts and actions of customers.

Schickenberg et al. (2008) indicate that nutrition neophobia customers are reluctant to try healthier foods. Previous studies have investigated the interaction between dietary neophobia in different food categories, in different cultural contexts, and different ages. Still, the mediating function of dietary neophobia across organic produce intake has not been investigated, especially in Vietnam, where the production of organic food is relatively low. The purpose of the research is, therefore, to fill this systematic gap by finding the context to consumer expectations and the moderating affect of dietary neophobia in consumer purpose and OF purchasing conduct of customers across Vietnam. Wai (2009) advised audiences not to underestimate customers in emerging markets such as China and India. However, Japan has established laws regulating and protecting the nation's OF standards. Indeed, with more than $61 \mathrm{OF}$ certification organs, Japan has been one of the largest global OF regulators (Rundgren, 2009). The OF sector across China is generating $30 \%$ per year attributable to abundant natural resources, government involvement assistance, instances of nutrition alarms and rising middle-class customers.

Next, India has been among the three nations with the highest volume of organic suppliers. India's international and domestic OF sectors are starting in tandem and may shortly potentially generate more than USD800 million (Menon, 2009). Moreover, a lack of data, skills and experience and healthy business strategies can impede the OF growth level 
in India. Vietnam has recorded over 1,022 organic farms covering 11,365 acres of land of green soil, and has been one of the world's leading sustainable coffee bean suppliers (Willer $\&$ Klicher, 2009). Furthermore, an organic fishery sector is emerging in Vietnam to generate oysters and fish. Vietnam's most prevalent organic farming products are vegetables and berries. Formal wholesalers and contemporary retail stores are fiercely facing competition from existing customers. Nevertheless, Vietnam's internal demand for OF is still considered to be significantly low (Sahota, 2009), partially due to Vietnam's cumulative annual personal income is around USD1,052.

\subsection{Hypotheses}

Health Awareness. Health awareness tests the ability to take extra measures. Safety-conscious consumers are mindful of their well-being and are driven to enhance and preserve their mental and physical health to avoid health problems by participating in healthy behaviors and just being wellbeingconscious (Newsom et al., 2005). These people tend to be conscious of diet and physical conditioning. Previous studies may have recognized health value as the primary motivation for buying organic food. It has also been observed that health awareness affects behavior, purpose and consumption of organic produce (Magnusson et al., 2003). Since consumers of organic products realize that food consumption impacts their wellbeing, they value normal and natural products. They are prepared to switch products to improve their quality of life. While not all research has confirmed the correlation regarding health awareness and attitude (Tarkiainen \& Sundqvist, 2005), the hypotheses are as follows:

H1a: Wellness awareness will positively influence the behavior toward organic production.

H1b: Health mindfulness will positively impact the willingness to buy organic products.

Ethical Self-identity. Moral or green consumers are environmentally responsible and buy environmentallysustainable goods, which are not destructive to the ecosystem or community. Ethical factors have been found to influence appetite for organic produce, including worries about the climate, the risk to livestock, the threat to human existence, and controversy about the increased use of animal-fed genetically engineered crops. Conscientious motivations define mindset and purpose regarding organic products. Ethical motives, furthermore, can lead to compassion as well as the ensuing emergence of different attitudes towards ethical concerns culminating in preferences of ethical consumerism. Moral motivations in this context might become part and parcel of the self-identity of customers (Shaw et al., 2000). Self-identification is described as the relevant section of the personal that corresponds to the specific behavior of a person. Previously, perceptions and motive were found to influence the purchasing of fair trade food. Throughout the sense of organic products, buying organic results can be an act of ethical conduct, and the hypotheses are as follows:

H2a: Ethical personality-identity will have a positive effect on the disposition toward organic products

H2b: Ethical personality-identity will have a positive impact on the obligation to buy organic products.

Food Safety Aspects. Overly concerned are sustainable consumers with the associated risks inherent in food intake. Food security would need the worry of customers regarding traces of pesticides and herbicides, fertilizers and artificial ingredients in food, and protection is often related to practices of agriculture (Yee et al., 2005). While food safety includes other factors including microbial protection and safety connected to animal diseases, minimal food safety work in the sense of organic produce explores food safety in consideration of pesticide residues, pesticides and environmental contaminants. Consumers always seemed to conceive of food security in regards to pesticides. Additives and artificial sweeteners in foods, berries and refined carbohydrates that reflect a continuous security issue in food manufacturing, as contrasted to the safety connected to livestock diseases that is not continuously throughout the press. Customers agree that organically grown foods present fewer threats to customers than commercial food commodities. In particular, participants claimed that lower death problems associated with pesticides are correlated with ethically sourced goods being consumed and produced. Based on their willingness to sacrifice cash in exchange, organic produce purchasers are preoccupied regarding safety and quality (Krystallis et al., 2006). In a separate study on both the acquisition of fresh produce brands developed on value, McEachern and Schroder (2004) discovered that opinions on meat wellbeing played a function in shaping perceptions, belief of challenges concerning labeling and buying conduct. While previous research emphasizes production safety as a significant motivation for the purchase of organic produce (Padel \& Foster, 2005), its association with perceptions and purpose regarding organic produce is still to be systematically established. Food safety appears to be an essential indicator of perceptions and buying preferences towards organic products, the hypotheses are as follows:

H3a: Food safety issues will have a positive impact on the disposition against organic products.

H3b: Food hygiene concerns will have a positive impact on the buying intent of organic products. 
Mindset and Purpose. According to the Designed Behavioral Framework, perceptions in alternate meanings have been identified to have a positive correlation with action and emotional purpose. In the sense of buying organic products, perceptions clarify the intention of buying and the hypothesis is as follows:

H4: Attitude toward organic products will have a positive effect on purchasing intent.

The above findings are addressed systematically through the theoretical framework developed. The model describes health awareness, moral ego-identity and consideration for dietary safety as a background to the mentality towards organic products. It is expected that attitude regarding organic products and moral personality-identity are antecedents of intention.

\section{Research Methods and Materials}

To conduct this study by using highly organized methods, the analysts followed the positivism theoretical approach (Saunders et al., 2009). In the light of their population profiles, a deductive method was used to assess the opinions of OF respondents. The social research technique is an excellent addition to the accepted research methodology and methodology, as it helps investigators to gather qualitative data from a large target audience via a self-administered standardized checklist (McBurney \& White, 2007), owing to the existence of the complete analysis of OF customers' general preferences in various parts across the globe.

The sample population is Vietnamese people who have previously consumed OF, but still have the option of spending and buying OF within the coming years. The self-completion survey questions were distributed at many destinations all over Ho Chi Minh City, even in the area's supermarkets. Furthermore, a substantial number of individuals were selected on the central crossroads, but the researcher used selection queries to only attract participants living in Ho Chi Minh City. The investigator picked each fifth person from the central supermarkets were appropriate and met as many customers as possible on both major intersections.

Approximately a third of the respondents have dependent children below the ages of 16 residing at home with $68 \%$ being partnered or cohabitating. The age of the participants varied from 15 years old to above 65 years old. The questionnaire method was developed based on previous literature with defined indicators of disposition and purpose, whereas Shaw and Shiu (2003) applied moral self-identity. The product safety risk metric was modified from the measurements found in Roddy et al. (1996) as well as health sensitivity was calculated using Gould's (1988) metric.

\section{Results and Discussion}

Table 1 includes Cronbach's Alpha estimates for the outcomes of the measures and variable evaluation. The Alpha concentrations are higher than the minimum 0.7 standards (Hair et al., 1998). Furthermore, for each level, experimental factor analyzes disclosed that each framework is onedimensional with more than $50 \%$ of the variability described, with scree plotlines specifying one prevalent component per each structure.

Table 2 shows magnitude meaning and confidence intervals, and also extrapolations among the structures. A Mass Spectroscopy Determinant Assessment was then carried out in accordance with the usual conferences $(\mathrm{Hu} \&$ Bentler, $1999=0.984 \mathrm{CFI}=0.028 \mathrm{AIC}=118.339)$ and provided valuable tie $\left(\pi^{2}=50.339 \mathrm{df}=45 \mathrm{p}\right.$-value $=0.210 \mathrm{TLI}=0.9948$ $\mathrm{CFI}=0.9957 \mathrm{RMSEA}=0.028 \mathrm{AIC}=119.3339)$. All directions were important inside the CFA system $(p<0.001)$.

\section{Structural Model Analysis}

The conceptualization had been evaluated to establish whether perceptions arbitrate the interaction among food safety consciousness (FSC), health consideration (HC), and ethical self-identity (ESI) as well as purpose.

Table 1: Reliability and factor analysis results

\begin{tabular}{|l|c|c|c|c|}
\hline Variable & Number of observations & Alpha (Corr) & $\begin{array}{c}\text { \% variance } \\
\text { Extracted }\end{array}$ & $\begin{array}{c}\text { Eigen level } \\
\text { (level of Loading) }\end{array}$ \\
\hline Intention for buying OF & 2 & 0.97 & 92.89 & 2.69 \\
\hline Attitude towards OF & 3 & 0.96 & 95.78 & 1.89 \\
\hline Ethical self-identification & 3 & 0.79 & 89.01 & 1.80 \\
\hline Food nutrition Concern & 4 & 0.73 & 63.11 & 1.90 \\
\hline Health Awareness & 5 & 0.86 & 65.00 & 3.86 \\
\hline
\end{tabular}


Table 2: Meaning and confidence intervals

\begin{tabular}{|l|c|c|c|c|c|c|}
\hline Parameters & $\begin{array}{c}\text { Mean and standard } \\
\text { Deviation }\end{array}$ & $\mathbf{1}$ & $\mathbf{2}$ & $\mathbf{3}$ & $\mathbf{4}$ & $\mathbf{5}$ \\
\hline Purchase purpose & $3.03(2.01)$ & 1 & & & & \\
\hline Attitude towards OF & $1.51(1.33)$ & 0.56 & 1 & & & \\
\hline Ethical and self-identity & $1.24(1.16)$ & 0.40 & 0.38 & 1 & & \\
\hline Food and safety concern & $1.65(1.08)$ & 0.30 & 0.39 & 0.34 & 1 & \\
\hline Wellness Consciousness & $1.63(1.13)$ & 0.13 & 0.22 & 0.19 & 0.20 & 1 \\
\hline
\end{tabular}

Table 3: Regression analysis

\begin{tabular}{|l|c|c|c|c|c|}
\hline Regression analysis & B & $\boldsymbol{\beta}$ & SE & CR & SIG \\
\hline Perception $\rightarrow$ Intention & 0.75 & 0.54 & 0.089 & 8.77 & $* * *$ \\
\hline Moral self-identity (ESI) - Purpose & 0.34 & 0.22 & 0.101 & 3.44 & $* * *$ \\
\hline $\begin{array}{l}\text { Food Nutrition concern (FSC) - } \\
\text { Perception }\end{array}$ & 0.40 & 0.29 & 0.109 & 3.51 & $* * *$ \\
\hline Moral self-identity (ESI) - Perception & 0.34 & 0.30 & 0.089 & 4.00 & ${ }^{* * *}$ \\
\hline Health Awareness (HA) & 0.20 & 0.15 & 0.089 & 2.09 & $*$ \\
\hline
\end{tabular}

Table 4: Goodness of fit statistics

\begin{tabular}{|l|c|c|c|c|c|c|}
\hline $\mathbf{X}^{2}$ & $\mathbf{0 . 2 5 4}$ & $\mathbf{X}^{2} / \mathbf{d f}$ & CFI & TLI & RMSEA & AIC \\
\hline 51.639 & 0.254 & 1.123 & 0.986 & 0.966 & 0.013 & 115.564 \\
\hline
\end{tabular}

Sig'level at $5 \%$.

Four factors should be kept in a moderating results study, these factors include:

Independent variables (FSC, HC and ESI) have a considerable impact across the intermediary (approach) throughout the intended path.

The facilitator (attitude) has a significant impact across the conditional model (inclination) throughout the intended direction.

The explanatory variables (FSC, HC and ESI) have a substantial effect across the dependent model (intention) throughout the planned approach.

The regression coefficients throughout the expected course.

(Full arbitration) or decreased (limited mediation) is substantial. Details of such experiments on each model showed that behavior is entirely manipulated by FSC and $\mathrm{HC}$ as well as partly influenced by ESI. The final design findings are described in Table 3. Ultimately, the fit of the system is outstanding with all of the substantial routes between the indices as well as their corresponding construct $(\mathrm{p}<0.001)$. The procedure performed with an aim $\mathrm{R}^{2}$ level of 0.49 as well as a disposition of 0.35 .
Five of the seven hypotheses are scientifically-backed in aspects of the established assumptions; the hypothesis table summarizes the outcomes. Assistance for $\mathrm{H} 1 \mathrm{~b}$ as well as $\mathrm{H} 3 \mathrm{~b}$ has not been included in connection with the partnership among FSC as well as HC and purpose. Still, the behavior has performed a critical moderating function in both instances. Ultimately, these findings indicate that moral conscience-identity and product safety issues are also quite crucial factors that influence willingness to form behavior with moral personality-identity. Health awareness has only a minor part to play in influencing behavior.

Extant literature stresses health awareness as being the most fundamental reason for understanding attitudes and actions regarding organic produce. Contrary to this experimental channel and also in line with Tarkiainen and Sundqvist (2005) health awareness is indeed the least significant driving perceptions about organic products concerning moral conscience-identity and product safety issues. However, there has been no considerable correlation among health awareness as well as intention. Such results may indicate, unlike previous studies, that even though participants 
are aware of their well-being and might be sensitive to any improvements and accountable for the level of their wellbeing and identify fewer health advantages with organic products with minimal impact on buying incentive, among the most potent determinants of perceptions is identified to be food hygiene consideration, but not the purpose.

The results suggest that the favorable perceptions of participants regarding organic products are established critically as a result of their apprehension regarding food handlers; in specific as regards food contaminants from chemicals, artificial ingredients, flavorings and synthetic squirts. Food hygiene concerns, indeed, do not anticipate interest in purchasing organic products directly. Intention aspect only has an enormous effect on purpose and is therefore not as grave an ultimate model effect. Discovering the overall results indicates that moral ego-identity have a much greater influence across the purpose of buying ( 0.62 for moral personality-identity against 0.31 for dietary safety). Besides health awareness (multiplicative effect 0.16 on the plan) and responsibility for food security, conscientious self-identity has been found to describe both behavior and purpose against organic products. This result is consistent with previous work on reasonable trade retail transactions (Shaw \& Shiu, 2002).

The results also emphasize that ethical concerns can lead consumers to develop liberal attitudes regarding organic products, which then, in turn, lead to more generous consumer incentives. In particular, when ethical issues are fundamental to the personality-identity of persons, these would occur in a subsequent change of both behavior and purpose (Shaw \& Shiu, 2002), as indicated in the research. The results may suggest that the impact of selfish interests, including health and nutrition protection on mindset and expectation towards organic produce, will decline. In contrast, philanthropic motives, including ethical concerns, remain more critical at the moment in influencing perceptions and expectations in the sense of organic produce. Indeed, the three variables (moral self-identity, food hygiene consideration, and health awareness) clarified just $35 \%$ of the mindset. Participants may consider organic produce as no good than standard dietary concerning other buying parameters, such as, for instance, flavor, lengthier shelf life, performance or an aggregate relative value (Fotopoulos \& Krystallis, 2002). These considerations were not explicitly designed and could contribute to the mindset of further explanation. Another drawback is that a subsequent analysis would aim to address a more generalizable population comprising only rural customers. Customers in rural areas have different opinions and also as previous studies have indicated mindsets towards nutrition and shopping (Broadbridge \& Calderwood, 2002).

Rural areas have much less access to the right products, including fresh fruits and vegetables. That is a significant concern because natural foods are considered to get less recycle-life than traditional foods and perhaps small independent stores may be hesitant to stock these goods. Therefore, providing an option among organic and conventional products would lead in unique product options because limited shelf space of same conventionally grown product categories would have been taken up. Consequently, the results of this research cannot be applied to a broader population category that might be the subject of the study.

Another restriction has been the use of an auto-selecting survey that may present partiality throughout the research results. Still, the investigator conducting the research tried to limit the bias by randomly selecting necessary respondents and actively encouraging all passersby to take part throughout the investigation.

Previous studies record mixed findings on the impact of motivations on perceptions and purchasing intentions against organic production. Authors note essential as well as trivial relations (Tarkiainen \& Sundqvist, 2005) stressing that our comprehension of the function of motivations (health knowledge, food security). To some degree, the underlying use of organic products remains controversial. The work described in this document adds to information by first researching selfidentity throughout the sense of organic products and secondly by subsequently modeling health awareness, consideration for food security and conscientious personality-identity as determinants of perceptions and purpose concerning organic products. The results recorded in this research are significant in our comprehension of the importance of health awareness, consideration for food nutrition and ethical self-identity throughout the purchasing of organic products.

Findings suggest food hygiene issues and conscientious self-identity are the much beneficial determinants of organic production perceptions. Because of the results in this report, future studies may examine this concept in other relevant circumstances; the consideration for food security has gained little research consideration throughout the field of organic produce. Food safety concerns are also related to academics exploring consumer confidence, as they might be regarded as one of their aspects in selecting standard, natural or health food products. Similarly, while previous studies excluded as a motivation affecting perceptions, ethical personality-identity was discovered to predict perceptions as well as behavioral intention. They are emphasizing the need to examine the function of this architecture in product decision-making better. Ethical personality-identity can be applicable in different contexts as a concept, including activities related to the need for sustainable energy and pollution offset, for instance. However, observations throughout this study suggest that health awareness is the least essential motivation for determining attitudes towards organic products. This study confirms previous studies by (Magnusson et al., 2003), which suggests that well-being awareness is a motivation for influencing perceptions toward organic products, while at the same time contradicting Tarkiainen and Sundqvist (2005) who reject nutrition as an indicator of perceptions. 


\section{Conclusions}

These findings, furthermore, may imply that the importance of well-being conscious awareness is decreasing as a motivation for buying fresh organic produce. Human beings do seem to be motivated by other reasons, particularly food security and ethical considerations, to buy organic goods. Consequently, research is needed to shift away from' egocentric' motivations that might have influenced the acquisition of fresh produce initially and concentrate more on 'selfless' factors that can help clarify and forecast organic produce intake. Throughout this sense, selfless intentions can be the subject of future studies in similar contexts, involving environmentally friendly activities such as sustainable energy use and sustainability. Generally, such findings suggest that responsible customers and those associated with safety and quality are much more likely to experience complementary views and expectations regarding organic produce than fitness-conscious customers. Since organic produce has been identified as equally reliant on moral values, including food security, it may also have consequences for marketers of organic products, if selling organic produce to customers, such presumed advantages should be emphasized.

\section{References}

Alba, J. W., \& Williams, E. F. (2013). Pleasure principles: A review of research on hedonic consumption. Journal of Consumer Psychology, 23, 2-18.

Broadbridge, A., \& Calderwood, E. (2002). Rural grocery shoppers: Do their attitudes reflect their action? International Journal of Retail and Distribution Management, 30(8), 394-406.

Brunso, K. \& Scholderer, J. (2001). Consumer health consciousness and the organic food boom: Fact or fiction. Appetite, 37, 130.

Fotopoulos, C., Krystallis, A., \& Ness, M. (2003). Wine produced by organic grapes in Greece: Using means-end chains analysis to reveal organic buyers are purchasing motives in comparison with the non-buyers. Food Quality and Preference, 14(7), 549-566.

Hair, J. F., Anderson, R. E., Tatham, R. L., \& Black, W. C (1998). Multivariate Data Analysis. Englewood Cliffs, NJ: PrenticeHall International.

Kim, J. B., Lee, H. H., \& Yang, H. C. (2014). Proposal of Eco-M Business Model: Specialty Store of Eco-friendly Agricultural Products Joined with Suburban Agriculture. Journal of Asian Finance, Economics and Business, 1(4), 15-21. https://doi. org/10.13106/jafeb.2014.vol1.no4.15.

Krystallis, A., Fotopoulos, C. \& Zotos, G. (2006). Organic consumers profile and their willingness to pay (WTP) for selected organic food products in Greece. Journal of International Consumer Marketing, 19(1), 87-97

Lee, C. J., \& Lim, S. Y (2020). Impact of Environmental Concern on Image of Internal GSCM Practices and Consumer Purchasing
Behavior. Journal of Asian Finance, Economics and Business, 7(6), 241-254. https://doi.org/10.13106/jafeb.2020.vol7. no6.241

Magnusson, M. K., Avrola, A., Hursti Koivisto U. K., Aberg, L, \& Sjoden, P. O. (2003). Choice of organic foods is related to perceived consequences for human health and to environmentally friendly behavior. Appetite, 40, 109-117.

McBurney, D. H. \&White, T. L. (2007). Research Methods (7th ed.). Belmont, CA: Thomson Higher Education.

McEachern, M. G., \& Schroder, M. J. A. (2004). Integrating the voice of the consumer within the value chain: A focus on value-based labelling communications in the fresh-meat sector. Journal of Consumer Marketing, 21(7), 497-509.

Menon, M. K. (2009). Organic agriculture and market potential in India. In: H. Willer, \& L. Kilcher (Eds), The World of Organic Agriculture: Statistics and Emerging Trends (pp.140-143). IFOAM, FiBL, ITC, Bonn, Geneva.

Newsom, J. T., McFarland, B. H., Kaplan, M. S., Huguet, N., \& Zani, B. (2005). The health consciousness myth: Implications of the near independence of major health behaviors in the North American population. Social Science \& Medicine, 60, 433-43.

Nguyen, P. N. D., Nguyen, V. T., \& Vo, N. N. T (2019). Key Determinants of Repurchase Intention toward Organic Cosmetics. Journal of Asian Finance, Economics and Business, 6(3), 205-214. https://doi.org/10.13106/jafeb.2019.vol6. no3.205

Padel, S., \& Foster, C. (2005). Exploring the gap between attitudes and behavior: Understanding why consumers buy or do not buy organic food. British Food Journal, 107(8), 606-625.

Roddy, G., Cowan, C. A., \& Hutchinson, G. (1996). Consumer attitudes and behaviour to Organic foods in Ireland. Journal of International Consumer Marketing, 9(2), 41-63.

Roitner-Schobesberger, B., Darnhofer, I., Somsook, S., \& Vogl, C. R. (2008). Consumer perceptions of organic foods in Bangkok, Thailand. Food Policy, 33(2), 112-21.

Rundgren, G. (2009). More than a million farms certified by 481 certification bodies. In: H. Willer, \& L. Kilcher (Eds), The World of Organic Agriculture: Statistics and Emerging Trends (pp. 75-78). IFOAM, FiBL, ITC, Bonn, Geneva.

Sahota, A. (2009). The global market for organic food \& drink. In: H. Willer, \& L. Kilcher (Eds), The World of Organic Agriculture: Statistics and Emerging Trends (pp. 59-64). IFOAM, FiBL, ITC, Bonn, Geneva.

Sangroya, D., \& Kumar, J. (2017). Factors influencing buying behavior of green energy consumer. Journal of Cleaner Production, 151, 393-405

Saunders, M., Lewis, P., \& Thornhill, A. (2009). Research Methods for Business Students (5th ed.). Harlow, UK: Pearson Education.

Schnackenberg, B., Van Assem, P., Brug, J., \& de Vries, N. K. (2008). Are the Dutch acquainted with and willing to try healthful food products? The role of food neophobia. Public Health Nutrition, 11, 493-500. 
Shaw, D. S., \& Shiu, E. (2002a). The role of ethical obligation and self-identity in ethical consumer choice. International Journal of Consumer Studies, 26(2), 109-116.

Shaw, D. S., \& Shiu, E. (2003). Ethics in consumer choice: A multivariate modeling approach. European Journal of Marketing, 37(10), 1485-1498.

Shaw, D. S., Shiu, E., \& Clarke, I. (2000). The contribution of ethical obligation and self-identity to the theory of planned behavior: An exploration of ethical consumers. Journal of Marketing Management, 16, 879-894.

Siegrist, M., Shi, J., Giusto, A., \& Hartmann, C. (2015). Worlds apart. Consumer acceptance of functional foods and beverages in Germany and China. Appetite, 92, 87-93.

Sørensen, L. S., \& Andreasen, C. B. (Eds.) (2006). Darcof II: Danish Research in Organic Food and Farming systems 20002005. Rounborg, Holstebro.

Tarkiainen, A., \& Sundqvist, S. (2005). Subjective norms, attitudes and intentions of Finnish consumers in buying organic food. British Food Journal, 107(11), 808-822.

Tran, T. A., Pham, N. T, Pham, K. V., \& Nguyen, L. C. T. (2020). The Roles of Health Consciousness and Service Quality toward Customer Purchase Decision. Journal of Asian
Finance, Economics and Business, 7(8), 345-351. https://doi. org/10.13106/jafeb.2020.vol7.no8.345

Wai, O. K. (2009). Organic Asia - from back to nature movement \& fringe export to domestic market trend. In: H. Willer, \& L. Kilcher (Eds), The World of Organic Agriculture: Statistics and Emerging Trends (pp.134-138). IFOAM, FiBL, ITC, Bonn, Geneva.

Wier, M., Doherty, K. O., Laura, M., \& Millock, K. (2008). The character of demand in mature organic food markets: Great Britain and Denmark compared. Food Policy, 33(5), 406-421. https://doi.org/10.1016/j.foodpol.2008.01.002

Willer, H., \& Kilcher, L. (Eds.) (2009). The World of Organic Agriculture: Statistics and Emerging Trends. IFOAM, FiBL, ITC, Bonn, Geneva.

Winter, C. K., \& Davis, S. F. (2006). Organic foods, Journal of Food Science, 71(9), 117-124.

Woo, E., \& Kim, Y. G. (2019). Consumer attitudes and buying behaviour for green food products from the aspect of green. British Food Journal, 121, 320-332.

Yee, W. M. S., Yeung, R. M. W., \& Morris J. (2005). Food safety: Building consumer trust in Livestock farmers for potential purchase behavior. British Food Journal, 107(10/11), 841-854. 